\title{
Cómo formar ciudadanos comprometidos con el patrimonio
}

\author{
Laura Lucas Palacios | historiadora del arte \\ URL de la contribución <www.iaph.es/revistaph/index.php/revistaph/article/view/3794>
}

Para conformar identidades y garantizar la protección de los bienes es fundamental estimular nuevos procesos selectivos que tomen en cuenta a los diferentes sectores de la sociedad. Para ello debemos de formar ciudadanos capaces de intervenir en el proceso de selección con sentido crítico, es decir, percibiendo su dimensión histórica y los intereses político-ideológicos que se ponen en juego (TEIXEIRA, 2006).

La llamada globalización y la búsqueda de recursos endógenos, con los que los territorios puedan competir mejor en un nuevo contexto de mercado, hacen del patrimonio un recurso inestimable. En los últimos años del siglo pasado se generaliza la idea, entre técnicos y políticos, de que el patrimonio es un factor de desarrollo local y territorial (FERNÁNDEZ, 2005). Instituciones internacionales como el Consejo de Europa y la UNESCO han elaborado numerosos documentos, desde los años ochenta del s. XX, que se inspiran en estos preceptos que esperan de la puesta en valor del patrimonio un retorno económico, social, cultural y territorial hacia la sociedad que los gestiona. En España algunas comunidades autónomas se suman al nuevo sesgo de la gestión patrimonial y elaboran documentos que asumen esta filosofía. Entre estas instituciones destaca la Junta de Andalucía que elabora documentos como Bases para una Carta sobre Patrimonio y Desarrollo en Andalucía en 1996 y la incorporación de esta nueva ideología patrimonial en el Plan General de Bienes Culturales.

La educación también recoge parte del contenido de estos aspectos patrimoniales, asumiendo que los recursos culturales identificados permiten concebir un aprovechamiento social si se gestionan adecuadamente. Esto no quiere decir que todos los bienes culturales puedan y deban ser puestos en valor socioeconómico, pero sí que muchos de ellos son susceptibles de ser movilizados entre los recursos de un colectivo para que, de forma sostenible, puedan reportar beneficios de forma colectiva e individual (FERNÁNDEZ, 2005). Desde esta perspectiva, la gestión del patrimonio es entendida como el conjunto de actuaciones programadas con el objeto de conseguir una óptima conservación de los bienes patrimoniales y un uso adecuado de ellos, que en las sociedades contemporáneas supone la superación de las concepciones tradicionales, especialmente en el período decimonónico, que se limitaban el cuidado o la tutela de los bienes patrimoniales para dar paso a la posibilidad de una política integral que se plantea no solamente conservar sino encontrar los mejores usos para el patrimonio cultural (GABARDÓN DE LA BANDA, 2007).

Incorporar el patrimonio como factor de desarrollo implica que los contenidos patrimoniales deban ser incorporados a muchas disciplinas de las que recibe el alumno y que, además, éstas deban establecer estrategias de comprensión compleja e interrelacionada de sus contenidos.

Este planteamiento interdisciplinar favorecería un conocimiento complejo de la realidad al permitir un análisis de los conflictos desde la lógica ecológica, la económica y social. Así, por ejemplo, la explotación turística y otros usos economicistas que se hacen del patrimonio, en muchos casos sí que están ligados al desarrollo económico y local, pero también a la especulación urbanística o modificaciones ecológicas. Comprobamos entonces, tal y como defiende Estepa (2009), que la educación patrimonial se configura como una praxis educativa y social que permite elaborar acciones pedagógicas que pretenden algo más que un estudio del pasado, abordando temas del currículum básico que atraviesan varias disciplinas como la educación ambiental, para la ciudadanía (personal, comunitaria, nacional, incluyendo los aspectos políticos y legales), las cuestiones económicas y de desarrollo tecnológico/industrial/social. Todas enfatizan 
la formación ciudadana, favoreciendo las economías locales a través del desarrollo turístico y de sostenibilidad, favoreciendo además el sentimiento de pertenencia y los lazos afectivos entre los miembros de una comunidad (TEXEIRA, 2006).

Según Fernández (2005) el patrimonio obliga a otra mirada al territorio y sus recursos, estableciendo homogeneidades, diferencias, concentraciones, carencias y, sobre todo, facilitando métodos para ponderar la importancia de unos sobre otros. A su vez, también propone reglas o métodos para entender qué recursos exógenos son necesarios para la creación de un determinado modelo de desarrollo y de cómo incorporar los recursos culturales que aportan inmigrantes o colectivos culturales minoritarios. Así, el objetivo de la gestión patrimonial se enfila no sólo a la conservación del patrimonio, sino a lograr la incorporación de los actores sociales en su gestión, como parte del desarrollo sostenible de la localidad. Lo cual implica no sólo identificar, diagnosticar, registrar, investigar, conservar y restaurar (áreas tradicionales de la gestión), sino también tomar en cuenta las dinámicas sociales y locales. Para ello es necesario promover estrategias que involucren a los ciudadanos y los hagan partícipes en la toma de decisiones en distintos niveles y responsabilidades.

Autores como García Canclini (2000), Martí (2001) y Chaparro (2001) manifiestan la ineludible relación que tiene el patrimonio con los habitantes, en la construcción de su identidad y su capital cultural. El patrimonio cultural como un espacio de complicidades sociales para definir el entorno y establecer formas de autorepresentación de la sociedad. Frente a esta realidad, surgen inquietudes sobre cómo crear estrategias educativas que potencien la valoración, conservación, el sentido de pertenencia y disfrute del patrimonio. En tal sentido la educación patrimonial surge como un área emergente de la educación y la gestión del patrimonio, cuyo objeto de estudio no se centra en los bienes, sino en la gente y en sus procesos de aprendizaje a través del patrimonio cultural (FONTAL, 2003; COLOM; SARRAMONA; VÁZQUEZ, 1998; PASTOR, 2004).
Por ello defendemos enseñar al alumno a participar en la toma de decisiones y en la gestión del patrimonio, capacitándolo para analizar, valorar y contrastar distintos puntos de vista, diferenciando el valor de cada uno de ellos y desarrollando actitudes acordes con la importancia de la preservación patrimonial (ESTEPA, 2009).

\section{BIBLIOGRAFÍA}

- ChaparRo, J. (2001) Apropiación social de espacios públicos: diseño, construcción y mantenimiento. En: Políticas y gestión para la sostenibilidad del patrimonio urbano. Bogotá: CEJA, 2001, pp. 137-147

- COLOM, A.; SARRAMONA, J.; VÁZQUEZ, G. (1998) Educación no formal. Barcelona: Ariel, 1998

- ESTEPA, J. (2009) La educación del patrimonio y la ciudadanía en el contexto español. En ÁVILA, R. M.; BORGHI, B.; MATTOZZI, I. (ed.) Lédicazione alla cittadinanza europea e la formazione degli insegnanti. Bolonia: Pàtron editore, vol. IV, 2009, pp. 353-362

- FERNÁNDEZ, V. (2005) Finalidades del Patrimonio en la educación. Investigación en la Escuela, 56, pp. 7-18

- FONTAL, O. (2003) Educación Patrimonial. Teoría y Práctica en el Aula, el Museo e Internet. Asturias: Trea, 2003

- GABARDóN DE LA BANDA, J. F. (2007) Educación y Patrimonio. La concienciación patrimonial en el ámbito educativo. En ÁVILA, R. M; LÓPEZ ATXURRA, J. R; FERNÁNDEZ DE LARREA, E. (ed.) Las competencias profesionales para la enseñanza-aprendizaje de las Ciencias Sociales ante el reto europeo y la globalización. Bilbao: Baster, 2007, pp. 427-436

- GARCíA CANCLINI, N. (2000) Consumidores y Ciudadanos. Conflictos Multiculturales de la Globalización. México: Grijalbo, 2000

- MARTí, M. (2001) Sobre el necesario vínculo entre el patrimonio y la sociedad. Reflexiones críticas sobre la interpretación del patrimonio. En I Congreso Iberoamericano del Patrimonio Cultural (Madrid, 29 y 30 de noviembre y 1 de diciembre de 2001). [Madrid]: Asociación Española de Gestores de Patrimonio Cultural, 2001

- PASTOR, M. (2004) Pedagogía museística. Nuevas perspectivas y tendencias actuales. Barcelona: Ariel, 2004

- TEIXEIRA, S. (2006) Educación patrimonial: alfabetización cultural para la ciudadanía. Estudios Pedagógicos, 32, pp. 133145 